\title{
Las videograbaciones académicas y las competencias de Ciencias Sociales en estudiantes de cuarto grado de secundaria de Huamachuco, Perú
}

\author{
Academic videotapes and Social Sciences competencies in fourth grade high school
} students from Huamachuco, Perú

\section{Elías Otiniano Reyes a ; eliasotiniano@ @otmail.com Orcid: https://orcid.org/0000-0001-8247-6720 \\ Juan Carlos Guerrero Alberca ${ }^{\text {b }}$ juan.carlos.chess@ hotmail.com \\ Orcid: https://orcid.org/0000-0003-1587-8521 \\ Sarai Huamani Pumacahua: saraih20@ hotmail.com}

\footnotetext{
${ }^{a}$ Docente de Ciencias Sociales. Egresado de la Universidad Católica de Trujillo. Trujillo Perú

${ }^{\mathrm{b}}$ Docente de Ciencias Sociales. Egresado de la Universidad Católica de Trujillo. Trujillo Perú.

'Docente de Educación Primaria. Universidad Nacional Intercultural de la Amazonia. Ucayali Perú
}

Recibido Julio/23/2020 • Aceptado: Agosto/02/2020 • Publicado: Septiembre/30/2020

\section{RESUMEN}

La investigación tuvo como objetivo determinar la relación entre videograbaciones académicas y las competencias de ciencias sociales de los estudiantes de cuarto grado de secundaria de la Institución Educativa № 80921 Nemesio Vargas Marquina Huamachuco. El tipo de investigación básica teórica, nivel descriptivo, con diseño correlacional, se usó el método hipotético deductivo, con una muestra de 60 estudiantes, se utilizó la técnica del examen con sus instrumentos la rúbrica para ambas variables. Para la correlación y prueba de hipótesis se hizo uso de coeficiente "r" de Pearson para la escala de intervalos. Se concluyó que existe relación directa y significativa las videograbaciones y las competencias de ciencias sociales en los estudiantes del cuarto grado de secundaria de la Institución Educativa N 80921 Nemesio Vargas Marquina Huamachuco, demostrado por Rho de Spearman de 0,339 y un p-valor de significancia de 0,000, a un nivel de 0,05 de significancia.

Palabras clave: Videograbaciones, competencias, ciencias sociales.

${ }^{a}$ Elías Otiniano - Reyes y ${ }^{\mathrm{b}}$ Juan Carlos Guerrero - Alberca Sarai ${ }^{\mathrm{c}} \mathrm{Huamani}$ - Pumacahua Articulo Protegido por Licencia Creative Commons: BY-NC-ND / Protected by Creative Commons: BY-NC-ND.

Sendas es una revista de acceso abierto / Sendas is an Open Access Journal. 


\section{ABSTRACT}

The objective of the research was to determine the relationship between academic video recordings and the social science competencies of the fourth grade students of secondary school of Educational Institution No. 80921 Nemesio Vargas Marquina Huamachuco. The type of basic theoretical research, descriptive level, with correlational design, the deductive hypothetical method was used, with a sample of 60 students, the examination technique was used with its instruments, the rubric for both variables. For the correlation and hypothesis testing, the Pearson's " $r$ " coefficient was used for the interval scale. It was concluded that there is a direct and significant relationship between video recordings and social science competencies in students in the fourth grade of secondary school of Educational Institution No. 80921 Nemesio Vargas Marquina Huamachuco, demonstrated by Rho de Spearman of 0.339 and a p-value of significance of 0.000 , at a 0.05 level of significance.

Keywords: Video recordings, competitions, social sciences.

\section{Introducción}

El mundo actual cuenta cada día con niños y jóvenes que pertenecen a la generación digital, un sector poblacional que nació después de la aparición del internet. Los adultos que no tuvieron la oportunidad de contar con estos beneficios en su formación se han visto obligados adaptarse a una nueva realidad, pero sobre todo capacitarse permanentemente en el uso y manejo de herramientas para poder funcionar al ritmo de la nueva generación. La incorporación a la tecnología en la educación aporta una serie de beneficios al sistema educativo actual, pues contribuye a la mejora y la eficiencia en el aula, productividad en el logro de aprendizajes,

\footnotetext{
${ }^{\mathrm{a}}$ Elías Otiniano - Reyes y ${ }^{\mathrm{b}}$ Juan Carlos Guerrero - Alberca Sarai ${ }^{\mathrm{c}}$ Huamani - Pumacahua Articulo Protegido por Licencia Creative Commons: BY-NC-ND / Protected by Creative Commons: BY-NC-ND. Sendas es una revista de acceso abierto / Sendas is an Open Access Journal.
} 
incrementa el interés de los estudiantes a las actividades académicas.

En la actualidad no existe estudiante alguno tampoco docentes que no cuenten con un equipo electrónico móvil en mano, es un elemento por así decirlo incorporado a la persona como lo es una prenda personal, ya que la infinidad de funciones y aplicativos audiovisuales ocupa gran parte del entretenimiento de las personas, que si bien es cierto tienen consecuencias negativas han ido convirtiéndose en fuente de información, instrucción y descubrimiento. El acceso a dispositivos móviles conectados al internet es cada vez más intuitivo, es innegable que han impuesto un giro brusco a las costumbres sociales lo que ha motivado un cambio de paradigmas en el uso de la tecnología. Estos cambios, son evidentes en el ámbito de la educación, donde cada vez muchas más cosas es posible realizar, con el aprovechamiento de la tecnología en red y posibilidades, ya sea en aula y fuera de ella.
Los problemas surgidos en el logro de aprendizaje de los niños de hoy, ya no es solo cognitivo, atencional, nutricional, los coeficientes intelectual y emocional, donde hay que dedicar investigar y hacer una serie de mejoras para lograr mejores resultados, sino que también la dificultad se encuentra en el desaprovechamiento de la tecnología, pues tanto los padres como maestros no están viendo como una herramienta educativa sino solamente material de entretenimiento. Constantemente se observa la incomodidad de los padres al apego de los niños hacia una Tablet, al celular o una PC conectada al internet. También un gran número de docentes privan el uso del celular a los estudiantes en la hora de clase, se persigue como si fuera una droga, algo prohibido que se debe desterrar, aun cuando el mismo docente no puede desprenderse del mismo.

Otro de las dificultades para la aplicación de la tecnología audiovisual en la educación peruana, son las políticas educativas, los diseños curriculares, que si

${ }^{\mathrm{a}}$ Elías Otiniano - Reyes y ${ }^{\mathrm{b}}$ Juan Carlos Guerrero - Alberca Sarai ${ }^{\mathrm{c}} \mathrm{Huamani}$ - Pumacahua Articulo Protegido por Licencia Creative Commons: BY-NC-ND / Protected by Creative Commons: BY-NC-ND. Sendas es una revista de acceso abierto / Sendas is an Open Access Journal. 
bien es cierto últimamente se han hecho innovaciones en la planificación en los criterios e indicadores de logro de aprendizajes, pero en cuanto a la metodología y ayuda audiovisual, hay poco, casi nada que pueda facilitar al docente usar en aula los videos o uso de equipos por alumno como estrategia a demostrar. Es por eso que los docentes muchas veces se rehúsan a utilizar los equipos electrónicos, o tienen poco interés en capacitarse para su uso de software, multimedia entre otros. Sin embargo, en la gestión docente si se está implementando sistemas de gestión y administración donde se está aplicando programas virtuales permanentes.

Por otro lado, la generación moderna de estudiantes nacida en el bum de la cibernética y la hiperactividad ha perdido el interés por la lectura, no hay jóvenes lectores, o sea lo niños y adolescentes que leen son por imposición del docente, ya que está condicionada a la entrega de un trabajo monográfico para una nota. El deseo de descubrir su aprendizaje en un libro ha disminuido en las nuevas generaciones por no decirlo que ha desaparecido; no es que sea un mal endémico pernicioso, sucede que el estudiante descubre aprendizajes por otros medios, que indudablemente son los medios tecnológicos. En vez de coger un libro prefiere ver un tutorial en Youtuber o leer fragmentos de textos resumidos en wilkipedia o simplemente activar un aplicativo de google académico para que le lea el texto deseado y escucharlo por audífonos mientras hace otras cosas.

En este orden de ideas ¿por qué no pedir las tareas académicas a los estudiantes del nivel secundario en videograbaciones cortas? ¿Cuánto ayudaría en los aprendizajes que los niños organicen sus ideas y lo expresen para el público utilizando su propio celular con cámara? ¿Por qué los docentes no podrían tener una página individual donde publiquen los trabajos de sus estudiantes?

Los estudiantes de la Institución Educativa $N^{\circ} 80921$ Nemesio Vargas Marquina del distrito de Huamachuco

${ }^{a}$ Elías Otiniano - Reyes y ${ }^{\mathrm{b}}$ Juan Carlos Guerrero - Alberca Sarai ${ }^{\mathrm{c}}$ Huamani - Pumacahua Articulo Protegido por Licencia Creative Commons: BY-NC-ND / Protected by Creative Commons: BY-NC-ND. Sendas es una revista de acceso abierto / Sendas is an Open Access Journal. 
provincia Sánchez Carrión en la Región la Libertad, en especial los de cuarto grado manifiestan un apego adictivo al uso de los celulares, casi el $95 \%$ cuenta con un celular y en su mayoría con pantalla táctil y buena parte de ellos tienen conexión a internet. Si bien es cierto, la señal satelital de internet en esta ciudad es algo inestable, pero existe el servicio de varias operadoras telefónicas que le hace más competitivo este servicio.

Por otro lado, los aprendizajes de los estudiantes en el área de Ciencias Sociales en los últimos años no han sido muy alentadoras, la mayoría está debajo del promedio, se considera que es debido al poco apoyo de los padres, o la escasa variedad de estrategias metodológicas utilizadas por los docentes, ya que siempre se aplica lo rutinario, el dictado, las tareas a casa para entregar voluminosos anillados como muestra de buen trabajo, entre otros.

Pérez \& Hortigüela (2016) en su estudio "Las grabaciones y los video tutoriales como recurso para evidenciar el aprendizaje" de la I Jornada de Buenas
Prácticas de Evaluación formativa en Docencia Universitaria, realizada por la Universidad de León, se llegó a la siguiente conclusión: la presentación y entrega de trabajos producidos por parte de los alumnos ha mejorado. La calidad del feedback proporcionado a los alumnos, tanto durante la realización de las prácticas como en la elaboración de las actividades, ha permitido que los resultados de los microgrupos mejoren tanto como ellos decidiesen. Se ha mejorado y facilitado la calificación y, sobre todo, ha aumentado de manera significativa la motivación de los alumnos implicados por adquirir el aprendizaje de las habilidades; objetivo fundamental de la experiencia.

Por otro lado, Cabrera Solano \& Castillo Cuesta (2019) citado por Ramírez Paredes (2019) en su estudio " $L a$ grabación colaborativa de videos para fortalecer la expresión oral en inglés" de la Universidad Técnica Particular de Loja, Ecuador, concluyó: La grabación de videos a través de teléfonos inteligentes constituye un excelente recurso para

${ }^{a}$ Elías Otiniano - Reyes y ${ }^{\mathrm{b}}$ Juan Carlos Guerrero - Alberca Sarai ${ }^{\mathrm{c}}$ Huamani - Pumacahua Articulo Protegido por Licencia Creative Commons: BY-NC-ND / Protected by Creative Commons: BY-NC-ND. Sendas es una revista de acceso abierto / Sendas is an Open Access Journal. 
fortalecer la destreza de hablar en inglés como lengua extranjera, pues permite mejorar el manejo de vocabulario, la fluidez, la pronunciación, y el uso de estructuras gramaticales en esta lengua. $\mathrm{La}$ estrategia de grabación de videos interactivos fomenta el trabajo colaborativo y genera una mejor relación docente - estudiante en el nivel universitario. Además, permite que los futuros docentes intercambien ideas que les ayuden a mejorar su capacidad de expresión oral en el idioma inglés como lengua extranjera.

Mientras que Sein, Fidalgo, \& García (2017), en su estudio "Trabajo en equipo y Flip Teaching para mejorar el aprendizaje activo del alumnado". Se demostró la eficacia de la utilización de los vídeos generados por el alumnado, que las puntuaciones obtenidas en el trabajo final son muy similares, aunque son algo superiores las de grupo experimental no hay diferencias significativas. Este hecho demuestra la viabilidad de los vídeos generados por el alumnado como recurso didáctico a utilizar en la actividad en casa de Flip Teaching y, por tanto, valida el modelo APFT propuesto en este trabajo de investigación.

Chávez (2018), investigó "Elaboración de tareas académicas en videos didácticos para desarrollar competencias en el curso de habilidades gerenciales en estudiantes del IX ciclo de las universidades privadas de Huancayo". Concluyó que: la elaboración de tareas en videos didácticos favorece significativamente en el desarrollo de competencias en el curso de habilidades gerenciales en los estudiantes del IX ciclo de administración de las universidades privadas de Huancayo; dado que la media aritmética del Pos test en el grupo experimental $(88,2)$ alcanza una significancia de $\mathrm{P}$-valor $=0$ menor a lo establecido del límite de error 0,05 para la investigación.

\section{Las Videograbaciones}

Por ser un término compuesto de relación objeto uso se trató de considerar aquellas definiciones conceptuales que más se acercan a la varaible de estudio.

${ }^{a}$ Elías Otiniano - Reyes y ${ }^{\mathrm{b}}$ Juan Carlos Guerrero - Alberca Sarai ${ }^{\mathrm{c}}$ Huamani - Pumacahua Articulo Protegido por Licencia Creative Commons: BY-NC-ND / Protected by Creative Commons: BY-NC-ND. Sendas es una revista de acceso abierto / Sendas is an Open Access Journal. 
Sendas. 1(3), Julio - Septiembre, 2020.

URL: https://www.revistas.infoc.edu.pe/index.php/sendas

Email: revistasendas@infoc.edu.pe

Orcasitas (2011) considera como "la imagen en movimiento que ha sido durante bastante tiempo una característica de la educación, desde sus inicios, hace más de un siglo, hasta estos últimos tiempos de frenético avance tecnológico".

Academicamente, Orcasitas (2011) define, "un video académico es una cuestión de proyectar imágenes en movimiento y audio en forma conjunta. $\mathrm{La}$ integración permite que el estudiante asocie el video a los otros medios o canales de comunicación, logrando que encuentre la relación entre ambos".

Por su parte Garcia (2011) considera que el video aplicado a lo académico:

Es un importante dispositivo para la identificación de problemas y realidades desde tres dimensiones: la dimensión técnica, que implica un conocimiento previo por parte del investigador para hacer uso efectivo del vídeo como herramienta investigativa; la dimensión expresiva, que
Vol. 1, No 3, pp. 1-18 Septiembre 2020 ISSN $2708-6380$ https://doi.org/10.47192/rcs.v1i3.43

comprende las pautas del lenguaje propias de la imagen en movimiento; y la dimensión científica, que le confiere la investigación social al vídeo por la calidad y tipo de material que registra, a diferencia de otros usos del vídeo (publicitario, artístico, musical)".

Garcia (2011) hace el comentario de que "cada vez más se acepta la mediación del investigador frente al hecho que investiga y registra con su cámara. Bajo esta mirada, el vídeo no es solamente una manera de observar, estudiar y analizar el mundo a través de imágenes y sonidos, con una cierta distancia por parte del investigador, quien busca transmitir una supuesta "objetividad", sino que es, en ella misma, una creación”.

Como vemos, el video, "es un sistema de grabación y reproducción de imágenes, que pueden estar acompañadas de sonidos y que se realiza a través de una cinta magnética. Conocido en la actualidad por casi todo el mundo, consiste en la captura de una serie de fotografías (en este

${ }^{a}$ Elías Otiniano - Reyes y ${ }^{\mathrm{b}}$ Juan Carlos Guerrero - Alberca Sarai ${ }^{\mathrm{c}}$ Huamani - Pumacahua Articulo Protegido por Licencia Creative Commons: BY-NC-ND / Protected by Creative Commons: BY-NC-ND. Sendas es una revista de acceso abierto / Sendas is an Open Access Journal. 
contexto llamadas «fotogramas») que luego se muestran en secuencia y a gran velocidad para reconstruir la escena original" (Pérez Porto \& Gardey, 2009)

Competencias del curso de ciencias sociales.

El área de Ciencias Sociales permite que los estudiantes de la Educación Básica se formen como ciudadanos conscientes de la sociedad donde viven y de su rol como sujetos históricos a fin de que asuman compromisos y se constituyan en agentes de cambio de la realidad social a través de la gestión de los recursos ambientales y económico MINEDU (2016)

\section{Competencia}

Desarrolla las competencias; Construye interpretaciones históricas. Gestiona responsablemente el espacio y el ambiente. Gestiona responsablemente los recursos económicos. Currículo Nacional (2016)

\section{Construye interpretaciones}

históricas. El estudiante sustenta una posición crítica sobre hechos y procesos históricos que ayuden a comprender el siglo XXI y sus desafíos, articulando el uso de distintas fuentes, la comprensión de los cambios, permanencias, simultaneidades y secuencias temporales y la explicación de las múltiples causas y consecuencias de estos. Supone reconocerse como sujeto histórico, es decir, como protagonista de los procesos históricos y, como tal, producto de un pasado, pero que, a la vez, está construyendo su futuro.

\section{Gestiona responsablemente el} espacio y el ambiente. El estudiante toma decisiones que contribuyen a la satisfacción de las necesidades desde una posición crítica y una perspectiva de desarrollo sostenible -es decir, sin poner en riesgo a las generaciones futuras-, y participa en acciones que disminuyen la vulnerabilidad de la sociedad frente a distintos desastres. Supone comprender que el espacio es una construcción social dinámica, es decir, un espacio de interacción entre elementos naturales y sociales que se va transformando a lo largo del tiempo y donde el ser humano cumple un rol fundamental.

${ }^{a}$ Elías Otiniano - Reyes y ${ }^{\mathrm{b}}$ Juan Carlos Guerrero - Alberca Sarai ${ }^{\mathrm{c}} \mathrm{Huamani}$ - Pumacahua Articulo Protegido por Licencia Creative Commons: BY-NC-ND / Protected by Creative Commons: BY-NC-ND.

Sendas es una revista de acceso abierto / Sendas is an Open Access Journal. 
Gestiona responsablemente los recursos económicos. El estudiante es capaz de administrar los recursos, tanto personales como familiares, a partir de asumir una postura crítica sobre el manejo de estos, de manera informada y responsable. Esto supone reconocerse como agente económico, comprender la función de los recursos económicos en la satisfacción de las necesidades, y el funcionamiento del sistema económico y financiero.

\section{Gestiona el factor intercultural}

social. Respeta la diversidad cultural y sus características diferenciales de la sociedad actual socializando con los miembros de la comunidad educativa y entre grupos igualitarios con principios de construcción hacia una sociedad más democrática al visualizar, describir y valorar igualitariamente los modos de apropiación y reelaboración de significados entre diferentes grupos.

Lograr estas competencias en educación básica regular implica el uso de estrategias que combine la lectura, el análisis y la síntesis de la información proporcionada por el docente e investigada por el estudiante. Esto habilita al docente el uso de medios y recursos para su desarrollo, donde los medios digitales cumplen gran función como son los celulares con cámaras, cámaras independientes para la grabación, la edición y la producción intelectual fílmica a la medida del estudiante.

\section{$\underline{\text { Materiales y Métodos }}$}

La investigación es de tipo básica teórica, debido a que, tal como refieren Hernández, Fernández Y Baptista (2014 p. 135) el estudio busca la generación de nuevo conocimiento mediante la revisión de distintas teorías. No buscándose modificar de ninguna manera la realidad. Se aplicó el método científico. "El método científico es un procedimiento riguroso formulado de una manera lógica para lograr la adquisición, organización y exposición del conocimiento, tanto en su aspecto teórico como en su aspecto experimental”.

El método específico, por el alcance de la investigación es el descriptivo. " $E l$ método Descriptivo, según Hernández, (2010)

\footnotetext{
${ }^{\mathrm{a}}$ Elías Otiniano - Reyes y ${ }^{\mathrm{b}}$ Juan Carlos Guerrero - Alberca Sarai ${ }^{\mathrm{c}}$ Huamani - Pumacahua Articulo Protegido por Licencia Creative Commons: BY-NC-ND / Protected by Creative Commons: BY-NC-ND. Sendas es una revista de acceso abierto / Sendas is an Open Access Journal.
} 
Sendas. 1(3), Julio - Septiembre, 2020.

URL: https://www.revistas.infoc.edu.pe/index.php/sendas

Email: revistasendas@infoc.edu.pe

busca especificar propiedades, características

y riesgos importantes de cualquier fenómeno

que se analice”. (Describe tendencias de un

grupo o población)

Por las características mencionadas la investigación tiene un diseño descriptivo correlacional de corte transversal, dado que se trabajó con dos variables y la medición se hizo una sola vez. La muestra constituyo 60 estudiantes del cuarto grado de secundaria del Colegio "Nemesio Vargas Marquina" de la provincia de Huamachuco, La Libertad Perú. Para la recolección de datos se aplicó la rúbrica en ambas variables, luego de calcular la confiabilidad con el coeficiente de alfa de Crombach y la validez mediante el juicio de expertos. Para la prueba de hipótesis se hizo uso del coeficiente de " $r$ " de Pearson, por tratarse de datos cuantitativos en la escala de intervalos.

\section{$\underline{\text { Resultados }}$}

$\operatorname{Tabla} N^{\circ} 1$

Resultados descriptivos de la variable:

Videograbaciones académicas.

\begin{tabular}{lccc}
\hline \multicolumn{4}{c}{ Resultados de las Videograbaciones académicas } \\
Categoría & Rango & Frecuencia & Porcentaje \\
\hline Inicio & $(1-10)$ & 0 & $0 \%$ \\
Proceso & $(11-13)$ & 28 & $47 \%$ \\
Logro previsto & $(14-16)$ & 25 & $42 \%$ \\
Logro destacado & $(17-20)$ & 7 & $12 \%$ \\
Total & & 60 & 100.00 \\
\hline
\end{tabular}

Vol. 1, N ${ }^{\circ}$ 3, pp. 1-18 Septiembre 2020

ISSN $2708-6380$ https://doi.org/10.47192/rcs.v1i3.43

Nota: Categorización por rangos de las calificaciones de los estudiantes de cuarto grado sobre las videograbaciones en el Colegio "Nemesio Vargas Marquina”.

Fuente: Base de datos del instrumento de la investigación

Observando la tabla $\mathrm{N}^{\circ} 1$, se aprecia que de los 60 estudiantes evaluados con la rúbrica sobre el uso de las videograbaciones académicas en la Institución Educativa $\mathrm{N}^{\circ}$ 80921 Nemesio Vargas Marquina de Huamachuco, el $12 \%$ se encuentra en el nivel destacado, el $42 \%$ de estos estudiantes se encuentra en nivel logro previsto, el $47 \%$ se ubica en el nivel en proceso. Los estudiantes de cuarto grado de secundaria tienen un manejo lo suficiente de la tecnología digital a su alcance como son los celulares con cámara, utilizados en el proceso de su aprendizaje.

Tabla $N^{\circ} 2$

Resultados descriptivos de la
variable: Competencias de las ciencias
sociales

${ }^{\mathrm{a}}$ Elías Otiniano - Reyes y ${ }^{\mathrm{b}}$ Juan Carlos Guerrero - Alberca Sarai ${ }^{\mathrm{c} H u a m a n i}$ - Pumacahua Articulo Protegido por Licencia Creative Commons: BY-NC-ND / Protected by Creative Commons: BY-NC-ND. Sendas es una revista de acceso abierto / Sendas is an Open Access Journal. 


\begin{tabular}{llcc}
\hline \multicolumn{3}{c}{ Resultados de las Competencias de las ciencias sociales } \\
Categoría & Rango & Frecuencia & Porcentaje \\
\hline Inicio & $(1-10)$ & 5 & $8 \%$ \\
Proceso & $(11-13)$ & 26 & $43 \%$ \\
Logro previsto & $(14-16)$ & 24 & $40 \%$ \\
Logro destacado & $(17-20)$ & 5 & $8 \%$ \\
Total & & 60 & 100.00 \\
\hline
\end{tabular}

Nota: Categorización por rangos de las calificaciones de los estudiantes de cuarto grado sobre las competencias en el área de Ciencias Sociales en el Colegio "Nemesio Vargas Marquina”.

Fuente: Base de datos del instrumento de la investigación

Observando la tabla $\mathrm{N}^{\circ} 2$, se aprecia que de los 60 estudiantes evaluados con la rúbrica sobre las competencias de las ciencias sociales en la Institución Educativa $N^{\circ} 80921$ Nemesio Vargas Marquina de Huamachuco, el $8 \%$ se encuentra en el nivel destacado, el $40 \%$ de estos estudiantes se encuentra en nivel logro previsto, $43 \%$ se ubica en nivel en proceso y $8 \%$ se encuentra en nivel de inicio. Los estudiantes de cuarto grado de secundaria han logrado parcialmente las competencias de las ciencias sociales, son conscientes de la cultura económica, medioambiental e intercultural de su entorno.
Para la prueba de hipótesis con el estadígrafo, "r" de Pearson, por ser la más apropiada para los datos de escala intervalar, Oseda (2011)

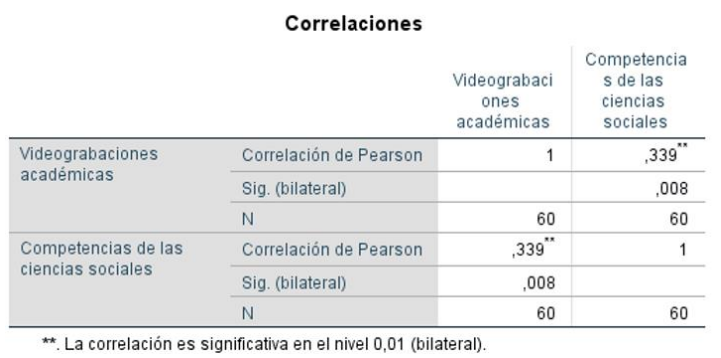

Ubicando el resultado se tiene que $r=0,339$, se encuentra entre el rango de $(0,25$ y 0,49$)$ lo que se ubica en la correlación considerado como correlación positiva débil entre las videograbaciones y la competencia de ciencias sociales en los estudiantes del cuarto grado de Educación Secundaria de la Institución Educativa $\mathrm{N}^{\circ}$ 80921 "Nemesio Vargas Marquina" de Huamachuco. Puesto que t calculada es mayor que "t" teórica $(2,74>1,96), r$ $(0,339)>0.10 ;$ sig. $0,000<0,05$ en consecuencia, se rechaza la hipótesis nula (Ho) y se acepta la hipótesis alterna (Hi). Se concluye que si existe una relación directa entre videograbaciones y la competencia de ciencias sociales en los

${ }^{\mathrm{a}}$ Elías Otiniano - Reyes y ${ }^{\mathrm{b}}$ Juan Carlos Guerrero - Alberca Sarai ${ }^{\mathrm{c}} \mathrm{Huamani}$ - Pumacahua Articulo Protegido por Licencia Creative Commons: BY-NC-ND / Protected by Creative Commons: BY-NC-ND. Sendas es una revista de acceso abierto / Sendas is an Open Access Journal. 
estudiantes del cuarto grado de Educación Secundaria de la Institución Educativa $\mathrm{N}^{\circ}$ 80921 Nemesio Vargas Marquina de Huamachuco; es decir $\mathrm{x}=\mathrm{tc}(2,74)>\mathrm{t}$ $(1,96)$.

\section{Discusión}

Los resultados de la investigación para cada variable fueron que, el uso de las videograbaciones académicas en los estudiantes se encuentra en un nivel de logro previsto en un $42 \%$ y logro destacado en $12 \%$, lo que nos indica que más del $50 \%$ de los estudiantes investigados del cuarto grado de secundaria del Colegio Nemesio Vargas Marquina de Huamachuco, utilizan para la tecnología digital móvil para las tareas académicas. Ellos usan los equipos móviles con cámaras para grabar las sesiones grupales y siguen un pequeño libreo para exponer el resumen de los temas investigados, corrigen ellos mismos entre ensayo y error para mejorar y presentar la mejor edición para la exposición oficial.
Aun cuando hay un $42 \%$ que no ha logrado ya que se encuentra en nivel de proceso, el uso de la tecnología móvil es una herramienta inmediata para los estudiantes de esta generación. La tecnología en la educación es cada vez una alternativa que se complementa con el método convencional presencial en aulas físicas. Al respecto, Garcia (2011) considera que el video aplicado a lo académico, "es un importante dispositivo para la identificación de problemas y realidades". Esto nos permite ratificar la metodología utilizada por los maestros como medios de aprendizaje para el logro de capacidades utilizando menos recursos físicos, ahorrando tempo y cuidando el medio ambiente con la reducción de uso de papel u hojas impresas.

Las competencias de las ciencias sociales en el Currículo Nacional, la evaluación realizada se tuvo que el $8 \%$ se encuentra en el nivel destacado y el $40 \%$ en el nivel de logro previsto; el 40\% está en el nivel de proceso y un $8 \%$ en inicio. Es así como se muestra que los estudiantes de cuarto grado de secundaria en la

${ }^{a}$ Elías Otiniano - Reyes y ${ }^{\mathrm{b}}$ Juan Carlos Guerrero - Alberca Sarai ${ }^{\mathrm{c}}$ Huamani - Pumacahua Articulo Protegido por Licencia Creative Commons: BY-NC-ND / Protected by Creative Commons: BY-NC-ND. Sendas es una revista de acceso abierto / Sendas is an Open Access Journal. 
Institución Educativa $\mathrm{N}^{\circ} 80921$ Nemesio Vargas Marquina de Huamachuco, han logrado parcialmente las competencias de las ciencias sociales, son conscientes de la cultura económica, medioambiental e intercultural de su entorno. El logro de estas competencias requiere de una socialización de los estudiantes, la revisión de bibliografía, conozcan la realidad. MINEDU (2016) sostiene que "el área de Ciencias Sociales permite que los estudiantes de la Educación Básica se formen como ciudadanos conscientes de la sociedad donde viven ...".

El coeficiente de correlación de "r" de Pearson con la cual se probó la hipóteisis, es de 0,339 que representa una correlación positiva débil. La corelación esxite, es significativa al 0,05 de probabilidad, sin enbargo aun es baja la correlación lo que nos expliqca que el uso de las videograbaciones tinen una proporción moderada en el logro de copetencias de las ciencias sociales, no odria ser una relación determinante. Para corroborar este resultado acudimos a lo recomendado por Hernández R. et.al
(2014) que refiere elevar al cuadrado la " $r$ " $(0,339)^{2}$ tendriamos 0,678 que en términos porcentuales seria $67.8 \%$, entendiendose que en una correlación causal seria que el suso de las videograbaciones incide en un $67.8 \%$ en el logro de competencias de las ciencias sociales de los estudiantes de cuarto grado y que la diferencia, o sea $32.2 \%$ se debe a otros factores no previstos en el presente estudio.

$$
\text { Resultados como estos }
$$

encontramos en la tesis de Chavez (2018) sobre presenrtacion de trabajos en videos didacticos para lograr competencias en habilidaes genrenciales con estudiantes de tres universidades, preentado en la Facultad de Educación de la Universidad Nacional Mayor de San marcos, donde se demostro su influencia de la varaible independiente, vieos didácticos hacia el logro de competencias de los estudiantes. Demostrandose asi que la tecnologia digital, las videograbaciones de los estudiantes automotivan hacer exposiciones mas innovadoras y a la prodducción intelectual en medios digitsles, pue se pueden difundir en

\footnotetext{
${ }^{a}$ Elías Otiniano - Reyes y ${ }^{\mathrm{b}}$ Juan Carlos Guerrero - Alberca Sarai ${ }^{\mathrm{c}} \mathrm{Huamani}$ - Pumacahua Articulo Protegido por Licencia Creative Commons: BY-NC-ND / Protected by Creative Commons: BY-NC-ND. Sendas es una revista de acceso abierto / Sendas is an Open Access Journal.
} 
cuentas yoyuber y facebook y dar a conocer sus investigaciones.

Asimismo, la tesis de Pérez \& Hortigüela (2016) "Las grabaciones y los video tutoriales como recurso para evidenciar el aprendizaje" de la I Jornada de Buenas Prácticas de Evaluación formativa en Docencia Universitaria, realizada por la Universidad de León, se llegó a la siguiente conclusión: haberse mejorado la presentación y la forma de entrega de las producciones por parte de los alumnos. Además, la calidad del feedback proporcionado a los alumnos, tanto durante la realización de las prácticas como en la elaboración de las actividades, ha permitido que los resultados de los microgrupos mejoren tanto como ellos decidiesen. Se ha mejorado y facilitado la calificación y, sobre todo, ha aumentado de manera significativa la motivación de los alumnos implicados por adquirir el aprendizaje de las habilidades; objetivo fundamental de la experiencia.

La teoria de la comunicación nos muestra la evolución que ha transcurrido la humanidad, desde la comunicación con diseños graficos, la comunicación hablada, luego impresa, hasta llegar a la expresión en grabaciones usando equipos tecnológicos, fueron siempre innovaciones de cada generación. Havelock (Citado por Castells, 1997); tuvo lugar así "la separación del hablante de lo hablado. La posibilidad de un discurso basada en el conocimiento de la comunicación acumulativa. Marca el inicio de una separación del escrito con lo simbólico audiovisual, de esta manera, las imágenes $\mathrm{y}$ los sonidos quedan relegadas a las artes". Con la aparición de los medios audiovisuales se extiende una nueva cultura que capta los sonidos y las imágenes que antes fueron relegadas a las artes favoreciendo ahora la comunicación sensorial más que la racional. Posteriormente, aparecida la televisión y su difusión se experimentan cambios en los medios de comunicación, por lo que la trasmisión y reproducción de mensajes serian diferentes; pierde carácter central la radio, pero mantiene cierta cobertura de público por su flexibilidad y adaptabilidad a la cotidianidad de la gente. Al mismo

${ }^{a}$ Elías Otiniano - Reyes y ${ }^{\mathrm{b}}$ Juan Carlos Guerrero - Alberca Sarai ${ }^{\mathrm{c}} \mathrm{Huamani}$ - Pumacahua Articulo Protegido por Licencia Creative Commons: BY-NC-ND / Protected by Creative Commons: BY-NC-ND. Sendas es una revista de acceso abierto / Sendas is an Open Access Journal. 
tiempo los filmes, las películas se aglomeran en las audiencias televisivas dando paso así a los efectos especiales de pantallas gigantes presentadas al público.

Podemos decir que las videograbaciones se convirtieron en alternativa impuesta por la tecnología a la proyección programática de la televisión y transformaron por completo los hábitos de audiencia por la capacidad y facilidad de grabar y fragmentar la televisión de manera incontrolada. Se puede afirmar que el vídeo transformó el único sentido de las imágenes en pantalla y complementó la experiencia de la vida con la televisión; es así como se dio la posibilidad de combinar los hechos noticiosos con la particularidad de las vivencias locales en canales pequeños de la televisión.

Por su parte la teoría de la sociedad del conocimiento, que significa utilizar los medios tecnológicos para desarrollar aprendizajes, o se apara hacer ciencia, nos convence cada vez más que la sociedad del conocimiento ha generado nuevas $y$ distintas formas de aprender. Abarca al contexto diversos medios de aprender, la diversidad de estilos de aprendizaje; es como la tecnología ha acercado a la globalización de las aulas de aprendizaje con el uso de telecomunicaciones (Sánchez, 2001).

Es así como la investigación ha aportado a estas grandes teorías que, usando los equipos móviles con sus diferentes aplicaciones, aun en las familias de bajos recursos económicos pueden desarrollar aprendizajes, pueden motivas a los estudiantes a producir material educativo, pueden generar conocimiento y desarrollar diferentes habilidades como, desde lo tecnológico, cognitivo, expresivo y científico.

\section{Conclusiones}

Se determinó que pese a las transferencias económicas y los subsidios monetarios que suponen un apoyo para los sectores más golpeados por los efectos de la pandemia, no se ha logrado llegar ni a un $70 \%$ de avance de la ejecución del presupuesto asignado a las entidades públicas del gobierno regional y local de La Libertad, debido a la intervención de

${ }^{a}$ Elías Otiniano - Reyes y ${ }^{\mathrm{b}}$ Juan Carlos Guerrero - Alberca Sarai ${ }^{\mathrm{c}}$ Huamani - Pumacahua Articulo Protegido por Licencia Creative Commons: BY-NC-ND / Protected by Creative Commons: BY-NC-ND. Sendas es una revista de acceso abierto / Sendas is an Open Access Journal. 
Sendas. 1(3), Julio - Septiembre, 2020.

URL: https://www.revistas.infoc.edu.pe/index.php/sendas

Email: revistasendas@infoc.edu.pe

las irregularidades que cometen los "líderes "Existe relación directa y significativa entre las videograbaciones académicas y las competencias en el área de Ciencias Sociales en estudiantes de cuarto grado de secundaria de la Institución Educativa $N^{\circ} 80921$ Nemesio Vargas Marquina Huamachuco 2020, con coeficiente de " $r$ " de Pearson 0,339 y un nivel de significancia 0,05 ; se afirma que a mayor uso de las videograbaciones academias igual proporción se lograrán competencias en las ciencias sociales.

Existe relación directa y significativa existe las videograbaciones académicas y la competencia de Construcción de interpretaciones históricas en estudiantes de cuarto grado de secundaria de la Institución Educativa $\mathrm{N}^{\circ} 80921$ Nemesio Vargas Marquina Huamachuco 2020, con un coeficiente " $r$ " de Pearson de 0,269 y nivel de significancia al 0,05 se afirma que a mayor uso de las videograbaciones academias igual proporción se lograrán competencias de construcción de interpretaciones históricas.
Vol. 1, N³, pp. 1-18 Septiembre 2020

ISSN $2708-6380$ https://doi.org/10.47192/rcs.v1i3.43

Existe relación directa y significativa entre las videograbaciones académicas y la competencia de gestión responsable del espacio y del ambiente en estudiantes de cuarto grado de secundaria de la Institución Educativa $N^{\circ} 80921$ Nemesio Vargas Marquina Huamachuco 2020, con un coeficiente " $r$ " de Pearson de 0,228 y nivel de significancia al 0,05 se afirma que a mayor uso de las videograbaciones academias igual proporción se lograrán competencias de gestión responsable de los recursos económicos.

No existe relación directa $\mathrm{y}$ significativa entre las videograbaciones académicas y la gestión los recursos económicos en estudiantes de cuarto grado de secundaria de la Institución Educativa $\mathrm{N}^{\circ} 80921$ Nemesio Vargas Marquina Huamachuco 2020, con un coeficiente " $r$ " de Pearson de 0,179 y nivel de significancia al 0,05 se afirma que el uso de las videograbaciones academias no es significativo directo para el logro competencias de gestión responsable de recursos económicos.

${ }^{\mathrm{a}}$ Elías Otiniano - Reyes y ${ }^{\mathrm{b}}$ Juan Carlos Guerrero - Alberca Sarai ${ }^{\mathrm{c}} \mathrm{Huamani}$ - Pumacahua Articulo Protegido por Licencia Creative Commons: BY-NC-ND / Protected by Creative Commons: BY-NC-ND. Sendas es una revista de acceso abierto / Sendas is an Open Access Journal. 
Sendas. 1(3), Julio - Septiembre, 2020.

URL: https://www.revistas.infoc.edu.pe/index.php/sendas

Email: revistasendas@infoc.edu.pe

No existe relación directa y significativa entre las videograbaciones académicas y la gestión intercultural social en estudiantes de cuarto grado de secundaria de la Institución Educativa $\mathrm{N}^{\circ}$ 80921 Nemesio Vargas Marquina Huamachuco 2020, con un coeficiente "r" de Pearson de 0,169 y nivel de significancia al 0,05 se afirma que el uso de las videograbaciones academias no es significativo directo para el logro competencias de gestión intercultural social.

\section{$\underline{\text { Referencias }}$}

Cabrera Solano, P., \& Castillo Cuesta, L. (2019). La grabación colaborativa de videos para fortalecer la expresión oral en inglés. Ecuador: Universidad Técnica Particular de Loja.

Castells, M. (1997). La era de la información. Economía, sociedad y cultura. $L a$ sociedad red, 1.

Chávez Epiquén, A. (2018). “Elaboración de tareas académicas en videos didácticos para desarrollar competencias en el curso de habilidades gerenciales en
Vol. 1, N³, pp. 1-18 Septiembre 2020 ISSN $2708-6380$ https://doi.org/10.47192/rcs.v1i3.43

estudiantes del IX ciclo de as universidades privadas de Huancayo 2017. Lima: Universidad Nacional Mayor de San Marcos.

Garcia Gil, M. E. (2011). El vídeo como herramienta de investigación: Una propuesta metodológica para la formación de profesionales en Comunicación. El CES Felipe II, 13. Obtenido de http://www.cesfelipesegundo.com/re vista/articulos2011/Monica\%20Garci a.pdf

Hernández Sampieri, R., Fernandez Callado, C., \& Baptista Lucia, P. (2014). Metodología de la investigación. México: McGraw Hill Interamericana Editores.

MINEDU. (2016). Currículo Nacional del Perú. Obtenido de Ministerio de Educación:

http://www.minedu.gob.pe/curriculo/

Orcasitas Pacheco, L. J. (2011). El video digital. Conceptos, procesos $\mathrm{y}$ aplicaciones en el aula. Revista Comunicación(28), 109-114.

Obtenido de 17

${ }^{a}$ Elías Otiniano - Reyes y ${ }^{\mathrm{b}}$ Juan Carlos Guerrero - Alberca Sarai ${ }^{\mathrm{c}}$ Huamani - Pumacahua Articulo Protegido por Licencia Creative Commons: BY-NC-ND / Protected by Creative Commons: BY-NC-ND. Sendas es una revista de acceso abierto / Sendas is an Open Access Journal. 
https://revistas.upb.edu.co/index.php/

comunicacion/article/view/1200

Oseda D, Chenet M, Hurtado D, Chávez A.

(2015) Metodología de la Investigación -

Ed. Pirámide, Perú.

https://scholar.google.com/scholar?oi

$=$ bibs\&hl=es\&q=related:h6WPAlfxf

DwJ:scholar.google.com/

Pérez Porto, J., \& Gardey, A. (21 de Marzo de

2009). Definicion.de. Obtenido de

https://definicion.de/video/
Sánchez J. (2001). Aprendizaje visible, Tecnología invisible. Santiago de Chile: Ediciones Dolmen.

Sein, Fidalgo, \& García (2017), en su estudio "Trabajo en equipo y Flip Teaching para mejorar el aprendizaje activo del alumnado”. Artículo publicado en Revista. DOI: $10.26754 \quad$ I

CINAIC.2017.000001_129

Las videograbaciones académicas y las competencias de Ciencias Sociales en estudiantes de cuarto grado de secundaria de Huamachuco, Perú

(Elías Otiniano - Reyes) Por Revista Sendas se encuentra bajo una Licencia Creative Commons-No Comercial-Sin Derivadas 3.0 Uported.

${ }^{\mathrm{a}}$ Elías Otiniano - Reyes y ${ }^{\mathrm{b}}$ Juan Carlos Guerrero - Alberca Sarai ${ }^{\mathrm{c}}$ Huamani - Pumacahua Articulo Protegido por Licencia Creative Commons: BY-NC-ND / Protected by Creative Commons: BY-NC-ND. Sendas es una revista de acceso abierto / Sendas is an Open Access Journal. 